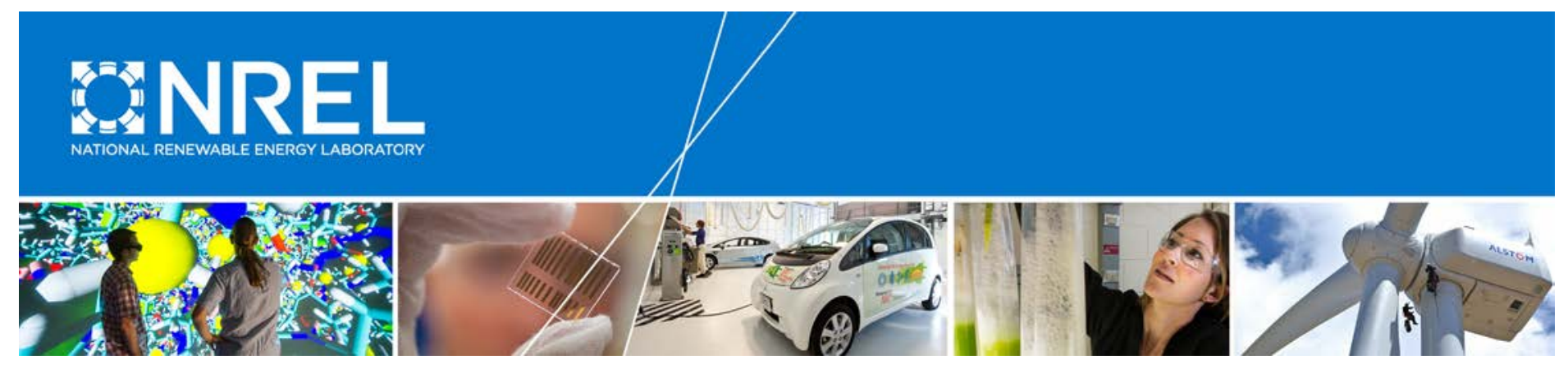

\title{
A Statistical Analysis of the Economic Drivers of Battery Energy Storage in Commercial Buildings
}

\section{Preprint}

Matthew Long

Dartmouth College

Travis Simpkins, Dylan Cutler, and Katie Anderson

National Renewable Energy Laboratory

Presented at the 2016 North American Power Symposium (NAPS)

Denver, Colorado

September 18-20, 2016

(C) 2016 IEEE. Personal use of this material is permitted. Permission from IEEE must be obtained for all other uses, in any current or future media, including reprinting/republishing this material for advertising or promotional purposes, creating new collective works, for resale or redistribution to servers or lists, or reuse of any copyrighted component of this work in other works.

NREL is a national laboratory of the U.S. Department of Energy Office of Energy Efficiency \& Renewable Energy Operated by the Alliance for Sustainable Energy, LLC

This report is available at no cost from the National Renewable Energy Laboratory (NREL) at www.nrel.gov/publications.

\section{Conference Paper}

NREL/CP-7A40-66832

November 2016 


\section{NOTICE}

The submitted manuscript has been offered by an employee of the Alliance for Sustainable Energy, LLC (Alliance), a contractor of the US Government under Contract No. DE-AC36-08GO28308. Accordingly, the US Government and Alliance retain a nonexclusive royalty-free license to publish or reproduce the published form of this contribution, or allow others to do so, for US Government purposes.

This report was prepared as an account of work sponsored by an agency of the United States government. Neither the United States government nor any agency thereof, nor any of their employees, makes any warranty, express or implied, or assumes any legal liability or responsibility for the accuracy, completeness, or usefulness of any information, apparatus, product, or process disclosed, or represents that its use would not infringe privately owned rights. Reference herein to any specific commercial product, process, or service by trade name, trademark, manufacturer, or otherwise does not necessarily constitute or imply its endorsement, recommendation, or favoring by the United States government or any agency thereof. The views and opinions of authors expressed herein do not necessarily state or reflect those of the United States government or any agency thereof.

This report is available at no cost from the National Renewable Energy Laboratory (NREL) at www.nrel.gov/publications.

Available electronically at SciTech Connect http:/www.osti.gov/scitech

Available for a processing fee to U.S. Department of Energy and its contractors, in paper, from:

U.S. Department of Energy

Office of Scientific and Technical Information

P.O. Box 62

Oak Ridge, TN 37831-0062

OSTI http://www.osti.gov

Phone: 865.576.8401

Fax: 865.576.5728

Email: reports@osti.gov

Available for sale to the public, in paper, from:

U.S. Department of Commerce

National Technical Information Service

5301 Shawnee Road

Alexandria, VA 22312

NTIS http://www.ntis.gov

Phone: 800.553 .6847 or 703.605 .6000

Fax: 703.605.6900

Email: orders@ntis.gov 


\section{A Statistical Analysis of the Economic Drivers of Battery Energy Storage in Commercial Buildings}

\author{
Matthew Long \\ Dartmouth College \\ Hanover, New Hampshire
}

\author{
Travis Simpkins, Dylan Cutler, Kate Anderson \\ National Renewable Energy Laboratory \\ Golden, Colorado \\ Travis.simpkins@nrel.gov
}

\begin{abstract}
There is significant interest in using battery energy storage systems (BESS) to reduce peak demand charges, and therefore the life cycle cost of electricity, in commercial buildings. This paper explores the drivers of economic viability of BESS in commercial buildings through statistical analysis. A sample population of buildings was generated, a techno-economic optimization model was used to size and dispatch the BESS, and the resulting optimal BESS sizes were analyzed for relevant predictor variables. Explanatory regression analyses were used to demonstrate that, of the variables considered, peak demand charges are the most significant predictor of an economically viable battery, and that the shape of the load profile is the most significant predictor of the size of the battery.
\end{abstract}

Keywords-batteries, energy storage, mathematical programming, Monte Carlo methods, regression analysis

\section{INTRODUCTION}

Batteries for utility bill savings have rarely been cost effective in the past, but this is beginning to change as new and improved storage technologies are developed and their capital costs continue to decline [1, 2]. Battery energy storage systems, or BESS, can capture revenue from multiple value streams, some of which include performing energy arbitrage, selling ancillary services to the grid, enabling participation in demand response programs, enabling transmission and distribution upgrades to be deferred, and reducing demand charges, or "peak shaving" [3-7]. They can also increase the energy resiliency of a site [8]. For this analysis, we will focus exclusively on behind-the-meter demand management.

Many utilities in the United States include a fixed dollar per kilowatt charge for a commercial consumer's peak demand to reflect the cost of infrastructure and maintenance associated with providing the power capacity. In areas with such demand billing, a BESS can reduce the peak demand charges by strategically discharging such that the electrical load is partially met from the stored energy thereby lowering the demand from the utility grid. The efficacy of a BESS at reducing peak demand varies, with some building types being very amenable to peak shaving, while others are not. In addition to utility bill savings for the building owner, peak demand reduction can be beneficial to utilities because a lower generation capacity has to be maintained.

In this paper, we explore the correlation between the costeffectiveness of a BESS and various input parameters such as location, installed cost of the technology, prevailing utility

This work was sponsored by the Department of Energy's Science Undergraduate Laboratory Internship program. tariff, the shape of the building load profile, and financial parameters including the discount rate and inflation rate. This work will help show which types of sites are good candidates for economical BESS as well as help policy makers understand how to structure incentives to promote BESS adoption.

\section{METHODOLOGY}

For this analysis we first constructed a sample population. We then found the optimal BESS size and resulting net present value (NPV) for each member in the population. Finally, we performed a regression analysis to explore the economic drivers that caused a BESS to be economically viable and influenced its sizing. This section describes the methodology in detail.

\section{A. Constructing the Sample Population}

The sample population consisted of 16 commercial building types across 15 climate zones in the continental United States, which represents an estimated $70 \%$ of the national commercial building stock [9]. Each building type and climate zone combination was equally weighted in the population. For each of those combinations, four cases were then generated with distinct economic parameters that were sampled from uniform distributions using a Monte Carlo technique. The population was further subdivided into a government sector dataset and a private sector dataset, each of which were analyzed separately. The federal sector dataset assumed a fixed discount rate (as required by 10 CFR 436A [10]) while the discount rate in the private sector was allowed to vary. This dataset construction resulted in a population of 940 different combinations of building type, climate zone, and uniformly sampled economic parameters for each of the private and federal sector populations.

\section{1) Building Load Profiles: The Department of Energy} commercial reference buildings were used as the basis for the buildings in the sample population. The commercial reference buildings are a set of building models consisting of 16 different space types in each of the 15 different climate zones across the contiguous United States [9]. An hourly load profile for each of the 240 building type / climate zone combinations was created using Energy Plus with typical meteorological year (TMY3) data for the given location [11]. The building types and locations considered are shown in Table 1. All building models were of the "post-1980" vintage. 
TABLE 1. BuILding Types, Cities, ANd Climate Zones Considered

\begin{tabular}{|l|l|l|}
\hline \multicolumn{1}{|c|}{ Building Type } & \multicolumn{2}{c|}{ Locations } \\
\hline Supermarket & Cities & Climate Zones \\
\hline Large Office & Miami, FL & 1A \\
\hline Medium Office & Houston, TX & 2A \\
\hline Small Office & Phoenix, AZ & 2B \\
\hline Warehouse & Atlanta, GA & 3A \\
\hline Strip Mall & Los Angeles, CA & 3B-Coast \\
\hline Stand-Alone Retail & Los Vegas, NV & 3B \\
\hline Large Hotel & San Francisco, CA & 3C \\
\hline Small Hotel & Baltimore, MD & 4A \\
\hline Quick Service Restaurant & Albuquerque, NM & 4B \\
\hline Full Service Restaurant & Seattle, WA & 4C \\
\hline Hospital & Chicago, IL & 5A \\
\hline Outpatient Health Care & Boulder, CO & 5B \\
\hline Primary School & Minneapolis, MN & $6 \mathrm{~A}$ \\
\hline Secondary School & Helena, MT & 6B \\
\hline Midrise Apartment & Duluth, MN & 7A \\
\hline
\end{tabular}

The commercial reference buildings dataset also includes a representative tariff structure for the local utility in each geographical location. The majority of the tariff structures included consist of flat usage charges and simple monthly demand rates. Those tariffs specifying time-of-use rates for either usage or demand were converted to flat usage (by dividing annual usage cost by annual usage) and simple monthly demand (by dividing monthly demand costs by monthly peak demand), respectively.

\section{B. Determining the Optimal Battery Sizing}

We assumed that each member building in the population had an optimally sized battery installed and that it was perfectly dispatched such that the life cycle cost of electricity was minimized. The optimal sizing and dispatching was found using the REopt modeling platform for energy system integration and optimization [12].

Formulated as a mixed integer linear program, the REopt model determines the optimal selection, sizing, and dispatching of technologies chosen from a candidate pool such that the electrical load is met in every time step at minimum life cycle cost. The candidate pool of technologies typically includes renewable and conventional distributed energy resources, the utility grid, energy storage technologies, and dispatchable loads. For the purposes of this analysis, however, the model could only consider battery storage and the grid.

For this study, the inputs to the model for each run consisted of the load profile for the site, the cost of purchasing electricity from the grid (both usage and demand) as well as the rate that those charges were expected to escalate in the future, the cost of installing a BESS, a general inflation rate, and the discount rate.

The output of the REopt model is generally a set of selected technologies, their sizing and dispatching at every hour, and the resulting life cycle cost. The NPV of the solution can easily be found by subtracting the life cycle cost of the current case from the base case in which only the grid is used to meet the electrical load. For this analysis, we were primarily interested in the battery sizing, which, of course, could be zero, indicating that a BESS was not economical in that scenario.

1) Battery Assumptions: The round trip efficiency of the BESS was assumed to be $80 \%$. It was assumed that the battery and associated power electronics were capable of charging and discharging within a single time step of one hour. That is, the battery was assumed to have a C-rate of 1 . Degradation of the battery due to cycling was not considered.

2) State Variables: The uncertain variables in the Monte Carlo simulation consisted of the inflation rate, electricity cost escalation rate, battery costs, and discount rate. Values for each of these variables were randomly sampled from a uniform distribution, the range of which was determined by considering past trends, published estimates, and experts in the field. The battery cost was assumed to include the capital cost for the battery and the associated inverter, as well the net present value of any maintenance costs. Ranges for the state variables are summarized in Table 2 .

3) Normalizing the Output of the REopt Model: The REopt optimization model outputs optimal battery size and the NPV for each run. The absolute battery size and NPV cannot be compared across building types, however, because the range of total electric consumption is so large. For example, an NPV of $\$ 10,000$ at an energy intensive site such as a hospital is much less significant than similar savings at a small office building. To compare battery sizes across the entire population, we normalized the battery size as

$$
B_{r e l}=\frac{B_{a b s}}{C_{t o t}}
$$

where $B_{a b s}$ is the battery size output from the REopt model, $C_{t o t}$ is the total annual energy consumption, and $B_{r e l}$ is the relative battery size after normalization.

4) Quantifying the Impact of Load Profile Shape: The efficacy at which the BESS is able to perform demand management is influenced by the shape of the electrical load profile. In the case of a perfectly flat load profile, for example, there are no peaks for a BESS to shave, and it would therefore be unable to reduce the utility demand charges at all. Conversely, the best case load profile shape would consist of a

TABLE 2. STATE VARIABLE RANGES

\begin{tabular}{|c|c|}
\hline Variable & Range \\
\hline Inflation Rate & $0 \%-3 \%{ }^{\mathrm{a}}$ \\
\hline Electricity Cost Escalation Rate & $0 \%-3 \%{ }^{b}$ \\
\hline Discount Rate (Private Sector) & $7 \%-10 \%{ }^{\mathrm{c}}$ \\
\hline Discount Rate (Federal Sector) & $3 \%{ }^{\mathrm{d}}$ (constant) \\
\hline Battery Cost & $\$ 600^{\mathrm{e}}-\$ 1500^{\mathrm{f}} / \mathrm{kWh}$ \\
\hline \multicolumn{2}{|c|}{$\begin{array}{l}\text { a. United States Department of Labor Bureau of Labor Statistics, "CPI Inflation Calculator." } \\
\text { b. Edison Electric Institute, "Assessing Rate Trends of U.S. Electric Utilities," Jan } 2006 . \\
\text { c. Oxera, "Discount rates for low-carbon and renewable generation technologies," April } 2006 . \\
\text { d. A. S. Rushing, J. D. Kneifel, and B. C. Lippiatt, "Energy Price Indices and Discount Factors for } \\
\text { Life-Cycle Cost Analysis - 2013," U.S. Department of Commerce National Institute of } \\
\text { Standards and Technology. } \\
\text { e. Martin LaMonica, "Ambri's Better Battery," MIT Technology Review, } 18 \text { Feb } 2013 . \\
\text { f. B. Dunn, H. Kamath, J. Tarascon, "Electrical Energy Storage for the Grid: A Battery of Choices," } \\
\text { Science 334, } 6058 \text { 928-935 (2011). }\end{array}$} \\
\hline
\end{tabular}


perfectly flat load with a single peak during one time period. In this case, a battery would be able to reduce the peak by an amount equal to it its power rating. The efficacy at which at a specific battery can perform demand reduction on a given load profile, $\eta_{D R}$, can be summarized as

$$
\eta_{D R}=\frac{P_{o l d}-P_{n e w}}{B}
$$

where $P_{\text {old }}$ is original peak demand, $P_{\text {new }}$ is the new peak, and $B$ is the size of the battery.

To include the load profile shape as a parameter in the sample population, we needed a load profile metric that represents the efficacy at which a BESS can perform demand reduction. The $\eta_{D R}$ metric by itself is not an adequate representation of overall amenability of a load profile to demand reduction because it is defined for a specific battery size.

In order to more generally quantify the efficacy at which a BESS of arbitrary size can perform demand reduction on a particular load profile, we created an aggregated metric referred to as the Load Profile Metric, or $L P M$. We computed the $L P M$ for each building type by first normalizing all of the load profiles to have the same annual consumption. We then performed a series of optimization runs to determine the maximum amount of demand reduction possible on a given load profile by a BESS of a specific size, which ranged from 0 $\mathrm{kWh}$ to $30 \mathrm{kWh}$ in $2.5 \mathrm{kWh}$ increments. The resulting 13 values of $\eta_{D R}$ were then averaged to create the $L P M$ for that building type. This process was then repeated for each of the 16 building types.

\section{Regression Analysis}

A logistic regression was performed to investigate the binary response variable of whether or not a BESS is costeffective. An ordinary least-squares regression (OLS) was performed to examine the factors influencing the sizing of the BESS. (Members of the population in which the optimal BESS size was zero were excluded from this analysis.) Each regression was conducted twice, once for the private sector dataset (varying discount rates) and once for the federal sector dataset (single, fixed discount rate).

Collinear predictor variables can be problematic in explanatory regression [13]. The variance inflation factor was used to measure collinearity, and correlated predictor variables were removed from full models. A backward selection procedure was used to select the variables for each of the four models with the Bayes Information Criterion (BIC) as the measure of model quality. The process began with a full model and removed a variable at each step until the BIC no longer decreased. If goodness of fit was the only selection criterion then the full model would always be selected, so a BIC-based selection procedure was chosen because it penalizes models with many variables that do not fit significantly better than those with fewer variables [14]. The assumptions that OLS and logistic regressions rely upon were tested using diagnostic plots. The variables considered for the models after collinearity testing are listed in Table 3 .

TABLE 3. VARIABLES CONSIDERED

\begin{tabular}{|l|l|}
\hline \multicolumn{1}{|c|}{ Variable Name } & \multicolumn{1}{c|}{ Variable } \\
\hline Average Monthly Peak Demand & $M_{\text {dem }}$ \\
\hline Average Demand Price & $P_{d e m}$ \\
\hline Average Usage Price & $P_{c o n}$ \\
\hline Load Profile Metric & $L P M$ \\
\hline Battery Cost & $B_{\text {cost }}$ \\
\hline Inflation Rate & $I$ \\
\hline Electricity Escalation Rate & $E$ \\
\hline Discount Rate (Private Sector) & $D$ \\
\hline
\end{tabular}

\section{RESULTS}

This section presents the results of the statistical analysis.

\section{A. Load Profile Metric}

The results of the LPM calculation are shown in Table 4. These demonstrate the estimated efficacy at which a battery can reduce peak demand in each of the 16 building types.

\section{B. Logistic Regression}

In a logistic regression, the response variable is the loglikelihood of the dichotomous variable outcome happening. In these models, $B_{\text {bin }}$ represents the probability that a BESS is economical. The logistic model for the federal dataset can be described as

$$
\begin{aligned}
& \log \frac{B_{b i n}}{1-B_{b i n}}=\alpha+\beta_{1} M_{d e m}+\beta_{2} P_{d e m}+\beta_{3} E+ \\
& \beta_{4} B_{c o s t}+\beta_{5} P_{c o n}+\beta_{6} L P M+\varepsilon
\end{aligned}
$$

$$
\begin{aligned}
& \left\{\alpha, \beta_{1}, \beta_{2}, \beta_{3}, \beta_{4}, \beta_{5}, \beta_{6}\right\}= \\
& \{-9.08,0.0038,2.20,1.79,-0.014,-0.23,7.43\}
\end{aligned}
$$

TABLE 4. BATTERY PEAK DEMAND REDUCTION EFFICACY

\begin{tabular}{|l|l|}
\hline Building Type & LPM \\
\hline Large Hotel & 0.959 \\
\hline Full Service Restaurant & 0.848 \\
\hline Medium Office & 0.831 \\
\hline Small Hotel & 0.807 \\
\hline Large Office & 0.754 \\
\hline Secondary School & 0.661 \\
\hline Small Office & 0.657 \\
\hline Primary School & 0.653 \\
\hline Quick Service Restaurant & 0.621 \\
\hline Strip Mall & 0.590 \\
\hline Stand-alone Retail & 0.561 \\
\hline Outpatient Health Care & 0.555 \\
\hline Warehouse & 0.549 \\
\hline Supermarket & 0.516 \\
\hline Hospital & 0.370 \\
\hline
\end{tabular}


The logistic model for the private sector dataset can be described as

$$
\begin{aligned}
& \log \frac{B_{b i n}}{1-B_{b i n}}=\alpha+\beta_{1} M_{d e m}+\beta_{2} P_{d e m}+\beta_{3} E+ \\
& \beta_{4} B_{c o s t}+\beta_{5} D+\varepsilon \\
& \left\{\alpha, \beta_{1}, \beta_{2}, \beta_{3}, \beta_{4}, \beta_{5}\right\}= \\
& \{8.16,0.0021,1.81,1.58,-0.016,-1.44\}
\end{aligned}
$$

The Wald z-statistics indicate that all the independent variables have a non-zero association with the dependent variable. To determine the relative importance of the variables to the dichotomous battery variable the standardized (beta) coefficients of the models were examined [15]. Table 5 shows the standardized coefficients for the predictor variables ranked by magnitude and thus by strength of association with the response variable.

TABLE 5. COEFFICIENTS FOR PREDICTOR VARIABLES

\begin{tabular}{|l|l|l|l|}
\hline \multicolumn{2}{|c|}{ Federal Sector } & \multicolumn{2}{c|}{ Private Sector } \\
\hline Variable & Standardized Coeff & Variable & Standardized Coeff \\
\hline$P_{\text {dem }}$ & 19.04 & $P_{\text {dem }}$ & 20.72 \\
\hline$B_{\text {cost }}$ & -7.41 & $B_{\text {cost }}$ & -11.48 \\
\hline$E$ & 3.15 & $E$ & 3.64 \\
\hline$M_{\text {dem }}$ & 3.10 & $D$ & -3.29 \\
\hline$P_{\text {con }}$ & -2.47 & $M_{\text {dem }}$ & 2.22 \\
\hline$L P M$ & 2.17 & \multicolumn{3}{|l}{} \\
\hline
\end{tabular}

Fig. 1 shows the probability that a BESS is economically viable for four of the model variables. In each case, the selected variable was varied over a range while the others were held constant.

\section{OLS Regression}

In order to transform the data into a normal state, a Box-Cox power transformation was performed on both the federal and private datasets. The results of the Box-Cox transformations indicated that a logarithmic transformation of the relative battery size response variable was appropriate for both models. More sophisticated methods for determining relative importance are available for linear regression than for logistic regression [16]. One such method, entitled LMG for its authors Lindeman, Merenda, and Gold, was used in the OLS regression and the results are displayed in Table 6 and Fig. 2 [17]. The OLS model for the federal dataset can be described as

$$
\begin{aligned}
& \log B_{r e l}=\alpha+\beta_{1} M_{d e m}+\beta_{2} P_{d e m}+\beta_{3} E+ \\
& \beta_{4} B_{c o s t}+\beta_{5} P_{c o n}+\beta_{6} L P M+\varepsilon
\end{aligned}
$$

$$
\begin{aligned}
& \left\{\alpha, \beta_{1}, \beta_{2}, \beta_{3}, \beta_{4}, \beta_{5}, \beta_{6}\right\}= \\
& \{-1.20,-0.00036,0.21,0.18,-0.0018,-0.044,5.04\}
\end{aligned}
$$
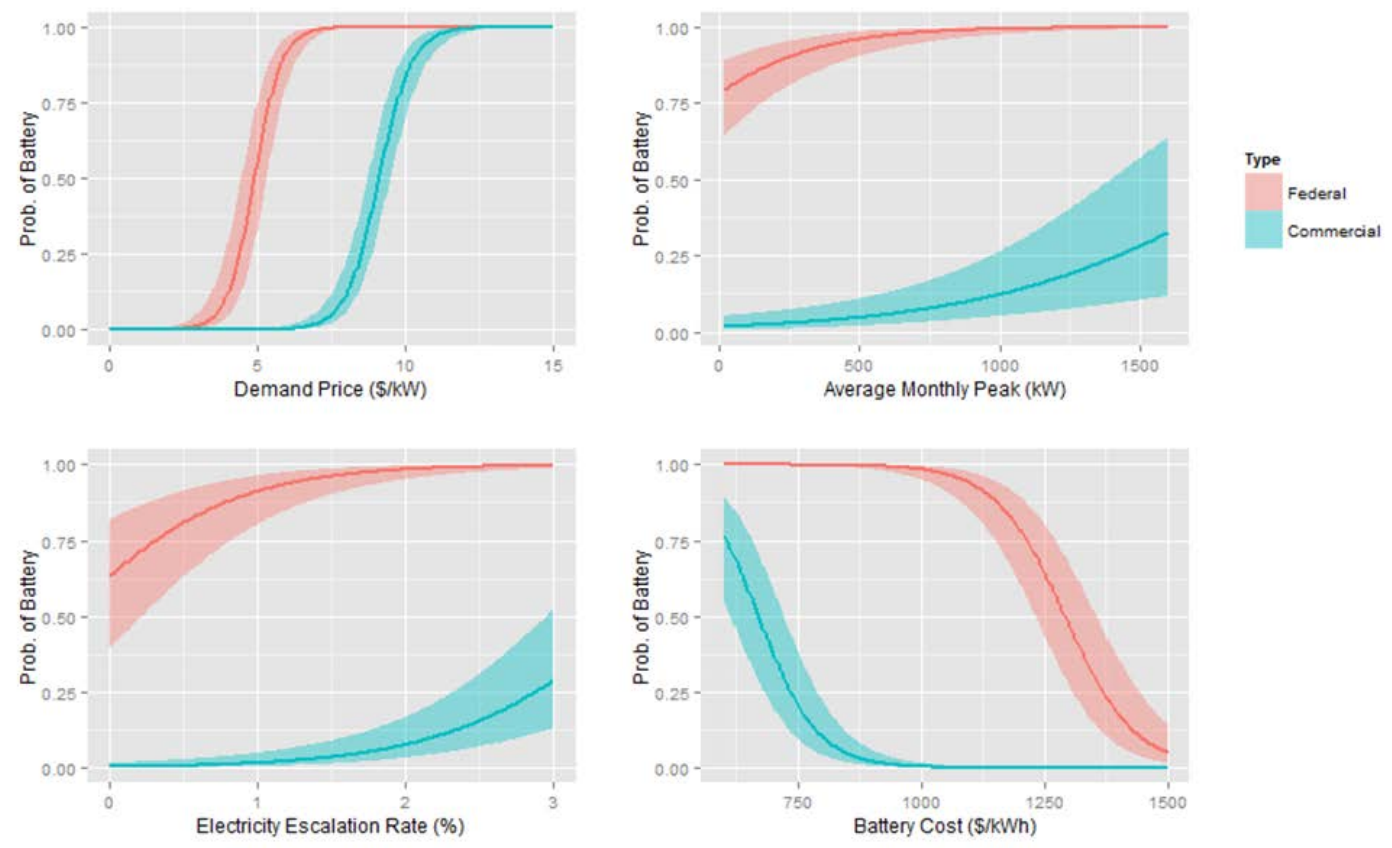

Fig. 1.Probability that a BESS is economical for four model variables. In each case, the selected variable is varied over a range while the others are held constant. $P_{d e m}=6.75 \$ / \mathrm{kW}, P_{\text {con }}=0.062 \$ / \mathrm{kWh}, E=2 \%, B_{\text {cost }}=1000 \$ / \mathrm{kWh}, M_{\text {dem }}=750 \mathrm{~kW}, L P M=0.5$ (federal sector only), $D=7.5 \%$ (private sector only) 


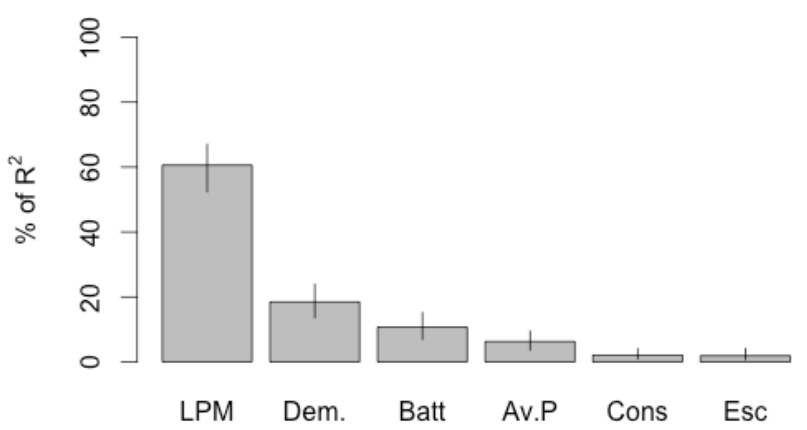

$\mathrm{R}^{2}=79.57 \%$, metrics are normalized to sum $100 \%$.

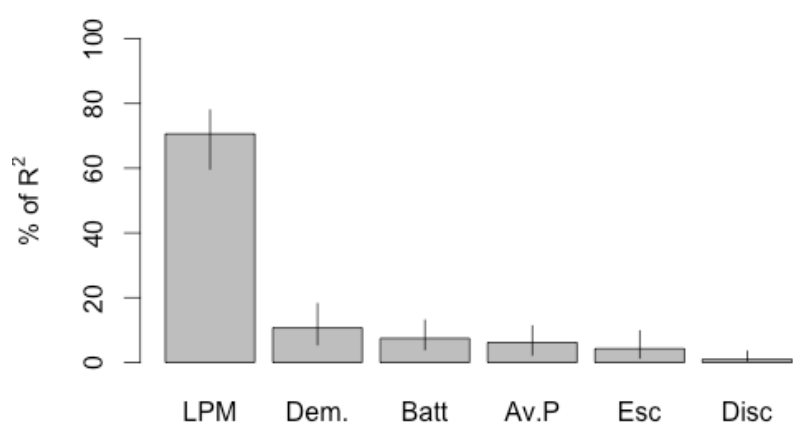

$\mathrm{R}^{2}=81.12 \%$, metrics are normalized to sum $100 \%$.

Fig. 2. Relative importance of predictor variables in both the (a) federal sector and (b) private sector datasets using the LMG method with $95 \%$ bootstrap confidence intervals.

The OLS model for the private dataset can be described as

$$
\begin{aligned}
& \log B=\alpha+\beta_{1} M_{d e m}+\beta_{2} P_{d e m}+\beta_{3} E+ \\
& \beta_{4} B_{\text {cost }}+\beta_{5} L P M+\beta_{6} D+\varepsilon
\end{aligned}
$$

$$
\begin{aligned}
& \left\{\alpha, \beta_{1}, \beta_{2}, \beta_{3}, \beta_{4}, \beta_{5}, \beta_{6}\right\}= \\
& \{-1.06,0.00024,0.26,0.32,-0.0026,5.79,-0.24\}
\end{aligned}
$$

\section{DISCUSSION}

From the logistic regression, it is observed that demand charge is the strongest predictor and battery cost is the second strongest predictor of whether or not a BESS will be economically viable. Reducing peaks with a BESS is only cost-effective in areas where demand charge savings can offset the cost of the BESS over the analysis period. Intuitively, higher demand charges (as a fraction of the total utility bill) increase the value of the peak-shaving performed by the battery. Conversely, lowering the cost of the battery decreases the savings required to justify the BESS. The financial variables of escalation rate and discount rate affect how the future energy savings are valued and thus are also predictors of the dichotomous BESS variable, albeit weaker ones. The average monthly peak demand variable is likely a predictor because in energy-intensive buildings the tariff structures are more likely to include demand charges. As there would be no benefit to peak-shaving without a demand charge, a BESS is never economical when there are no demand charges. Fig. 3 demonstrates this trend. It is interesting to note that the LPM, which represents the shape of the load profile, is a predictor variable, albeit a weak one, for the federal dataset, but insignificant for the private dataset. We hypothesize that this is because the lower discount rate used for the federal dataset renders what would otherwise be expensive options as more cost-effective, and as a result the shape of the load profile becomes mildly important.
TABLE 6. LMG RESULTS

\begin{tabular}{|l|l|l|l|}
\hline \multicolumn{2}{|c|}{ Federal Sector } & \multicolumn{2}{c|}{ Private Sector } \\
\hline Variable & LMG & Variable & LMG \\
\hline$L P M$ & 0.48 & $L P M$ & 0.57 \\
\hline$P_{\text {dem }}$ & 0.15 & $P_{\text {dem }}$ & 0.086 \\
\hline$B_{\text {cost }}$ & 0.086 & $B_{\text {cost }}$ & 0.060 \\
\hline$M_{\text {dem }}$ & 0.050 & $M_{\text {dem }}$ & 0.050 \\
\hline$P_{c o n}$ & 0.016 & $E$ & 0.034 \\
\hline
\end{tabular}

From the ordinary least-squares regression, we observe that the load profile metric created to quantify the effect of the load profile shape on BESS economics is the strongest predictor of optimal BESS sizing. If a BESS is proven to be cost-effective at a site, the LPM metric determines the marginal rate of return for adding additional battery size. A larger marginal rate of return means that the point at which adding additional battery capacity is no longer economical comes at higher BESS sizes, leading to larger cost-effective BESS sizes in general. This is illustrated in Fig. 4.

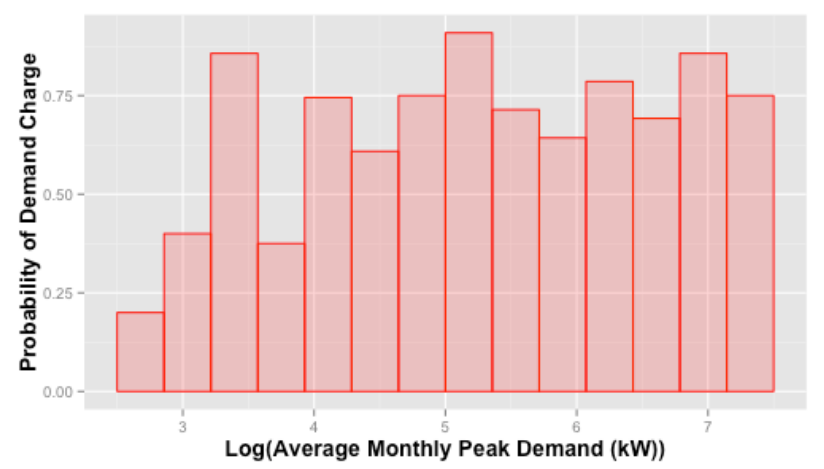

Fig. 3. Probability of having demand charges as a function of monthly peak demand. As the average demand peak increases, demand charges are more likely to be included in the tariff structure. 

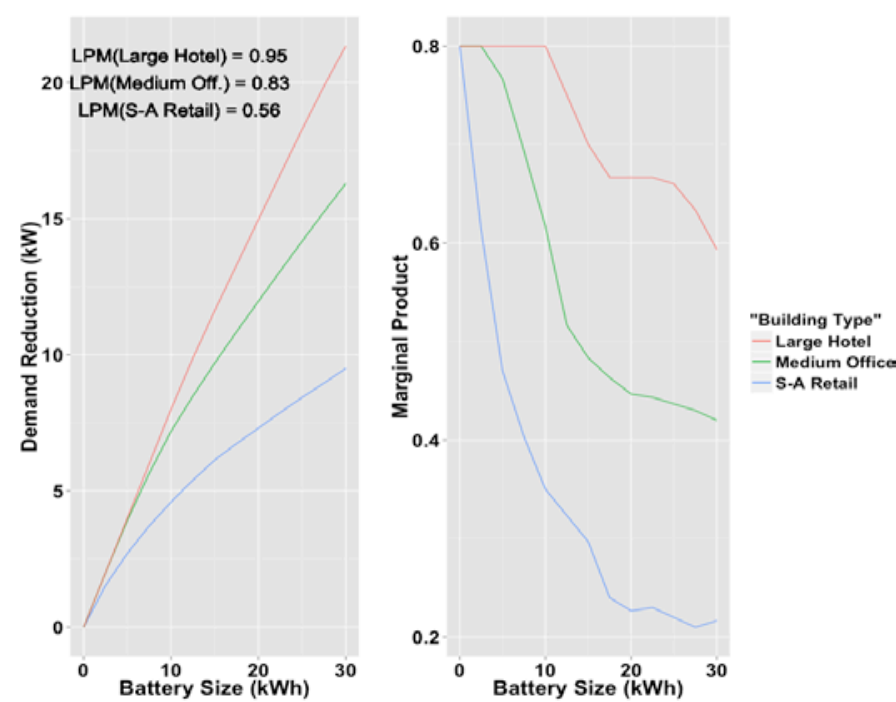

Fig. 4. (a) Normalized demand reduction as a function of BESS size. (b) Marginal product of the BESS size which is equivalent to the slope in (a). The lower marginal product for the Stand-alone Retail building type means that it is less beneficial to add a unit of battery size onto buildings of that type than it is the other two building types. Note that increasing rates of returns never occur as demand peaks cannot decrease in width as they are reduced.

\section{CONCLUSION}

In this paper we have shown that BESS are most likely to be economical when peak demand charges are high and battery costs are low. We have also shown that the shape of the load profile influences the sizing of cost-optimal BESS since it determines how much storage is required to reduce peak demand. While this work represents a preliminary study into the factors that influence BESS economics when behindthe-meter demand management is the primary revenue stream available, there remains much research to be done in this area. Research is currently underway at the National Renewable Energy Laboratory on BESS economics in residential, commercial, and utility-scale storage markets with a focus on stacking multiple value streams including demand management, energy arbitrage, ancillary services, demand response, transmission and distribution deferral, and energy resiliency.

\section{ACKNOWLEDGMENT}

This work was sponsored by the Department of Energy Science Undergraduate Laboratory Internships program which is coordinated at the National Renewable Energy Laboratory by Linda Lung. We would also like to thank Dan Olis and Emma Elgqvist for their helpful discussions regarding battery modeling and analysis.

\section{REFERENCES}

[1] S. Sun, "Lithium-ion battery cost forecast." Bloomberg New Energy Finance. July 3, 2013.

[2] "The Lithium Ion Inflection Point: Advanced Batteries and the Coming Boom in the Global Li-ion Market." Navigant Research. November 5, 2013 webinar.

[3] T. Simpkins, D. Cutler, B. Hirsch, D. Olis, and K. Anderson, "CostOptimal Pathways to 75\% Fuel Reduction in Remote Alaskan Villages," in Proc. Conf. on Technologies for Sustainability, Ogden, Utah, 2015.

[4] K. Bradbury, L. Pratson, D. Patino-Echeverri, "Economic viability of energy storage systems based on price arbitrage potential in real-time U.S. electricity markets," Applied Energy 114, pp. 512-519, 2014.

[5] K. Dasgupta, J. Hazra, S. Rongali, and M. Padmanaban, "Estimating Return on Investment for Grid Scale Storage within the Economic Dispatch Framework," in Proc. Conf. on Innovative Smart Grid Technologie Asia, Bangkok, Thailand, 2015.

[6] W. Su, "Economic analysis for demand-side hybrid photovoltaic and battery energy storage system," IEEE Transactions on Industry Applications 37, pp. 171-177, 2001.

[7] S. Teleke, "Rule-based control of battery energy storage for dispatching intermittent renewable sources," IEEE Transactions on Sustainable Energy 1, pp. 117-124, 2010

[8] T. Simpkins, K. Anderson, D. Cutler, D. Olis, "Optimal Sizing of a Solar-Plus-Storage System For Utility Bill Savings and Resiliency Benefits," accepted for publication in Proc. $7^{\text {th }}$ Conf. on Innovative Smart Grid Technologies, Minneapolis, MN, 2016.

[9] Deru et. al., "U.S. Department of Energy Commercial Reference Building Models of the National Building Stock," Febuary 2011.

[10] A. S. Rushing, J. D. Kneifel, and B. C. Lippiatt, "Energy Price Indices and Discount Factors for Life-Cycle Cost Analysis - 2013," U.S. Department of Commerce National Institute of Standards and Technology, 2014.

[11] Crawley et. al., "EnergyPlus: Energy Simulation Program," ASHRAE Journal 42, 49-56, 2000.

[12] T. Simpkins, D. Cutler, K. Anderson, D. Olis, E. Elgqvist, M. Callahan, and A. Walker, "REopt: A Platform for Energy System Integration and Optimization," in Proc. $8^{\text {th }}$ International Conf. on Energy Sustainability, Boston, MA, 2014.

[13] C. H. Yo, "An overview of remedial tools for collinearity in SAS," Proceedings of 2000 Western Users of SAS Software Conference 1, 2000.

[14] A. Rafferty, "Bayesian model selection in social research," Sociological Methodology 25, pp. 111-164, 1995.

[15] D. Thompson, "Ranking Predictors in Logistic Regression," Midwest SAS Users Group, 2009.

[16] U. Grömping, "Relative Importance for Linear Regression in R: The Package relaimpo," Journal of Statistical Software 17, 2006.

[17] R.H. Lindeman, P.F. Merenda, and R.Z. Gold, "Introduction to Bivariate and Multivariate Analysis," Glenview, IL, Scott, Foresman, 1980. 